\title{
Accessory Mineral Analysis of Alkali-rich Granite from Gejiu Tin District
}

\author{
Minghua Ren ${ }^{1 *}$ and Xiang Wang ${ }^{2}$ \\ 1. University of Nevada Las Vegas, Department of Geoscience, Las Vegas, Nevada, USA. \\ 2. Nanjing University, School of Earth Sciences and Engineering, Nanjing, P.R. China. \\ * Corresponding author: minghua.ren@unlv.edu
}

Microanalysis of accessory minerals has been applied to alkali-rich granitic rocks from one of the world largest tin deposits, Gejiu tin district, China. Accessory minerals in the granite can reach 3 volume percent and are usually volatile-bearing minerals. Other than regular phases like tourmaline, fluorite, and calcite, the accessory phases are HFSE and REE enriched phosphate, oxide, carbonate, and hydrated minerals, such as NbTa-oxides, bastnaesite, and stannite. Some of these minerals had been reported in the panning concentrates in the area, but they have never been systematically studied yet.

The current work shows that these minerals have distinctive chemical characters. In addition to the crystallization of cassiterite and wolframite, other mineral phases like niobian rutile, NbTa-oxides, and stannite also contain high Sn and W. BSE images indicate that accessory minerals are correlated with fluorite and calcite and distribute interstitially between alkali feldspar and quartz. Because of complicated substitutions between different ions, the EPMA elemental maps are the best way to show the heterogeneity of these minerals. The BSE image of phosphate shows that the churchite coats the monazite (Fig. 1a). For the NbTa-oxide, Ti enriched areas present as patches within the grain (Fig. 1b). This may indicate non-equilibrium crystallization of Ti-Nb-Ta during the mineral forming process. The lower oxygen content in these minerals compared with surrounding silicates in the oxygen maps indicated these minerals are hydroxide (Fig. 1c). For the trace elements in those minerals, WDS wavescan has been used to identify the elements and to select peak and background for quantitative analysis (Fig. 2a and b).

Based on the property of these minerals, the accessory minerals can be grouped into oxides, phosphates, sulfides, carbonates, and hydrated minerals. Oxides include cassiterite, niobian rutile, uraninite, wolframite, and thorite. Phosphates include apatite, cheralite, and monazite. Carbonates include calcite, manganoan siderite, bastnaesite, and synchisite. Sulfides include pyrite, chalcopyrite, galena, and stannite. Hydrated minerals include churchite, hydrated chernovite, hingganite, $\mathrm{NbTa}-\mathrm{oxides}$ of $\mathrm{Nb}-\mathrm{Ta}-$ Ti-Y-REE-W, scheteligite. This mineral assemblage in the alkali-rich granite indicates a volatile oversaturated condition $[1,2]$. Progressive fractional crystallization of the magma caused the extreme enrichment of incompatible ore-forming components, such as W, Sn, aqueous fluids, and other volatiles, in the residual magma [3]. When the regional tectonic environment evolved into the extensional regime at $\sim 72 \mathrm{Ma}$, the highly-fractionated residual magma ascended and formed the alkali-rich granite and the mineralized cassiterite-bearing quartz veins.

\section{References}

[1] M. Harlaux et al., Can. Min. 53 (2015), p. 653.

[2] P. Cerny et al., J. Geos. 52 (2007), p. 143.

[3] X. Wang and M. Ren, Ore Geo. Rev. 101 (2018), p. 453. 

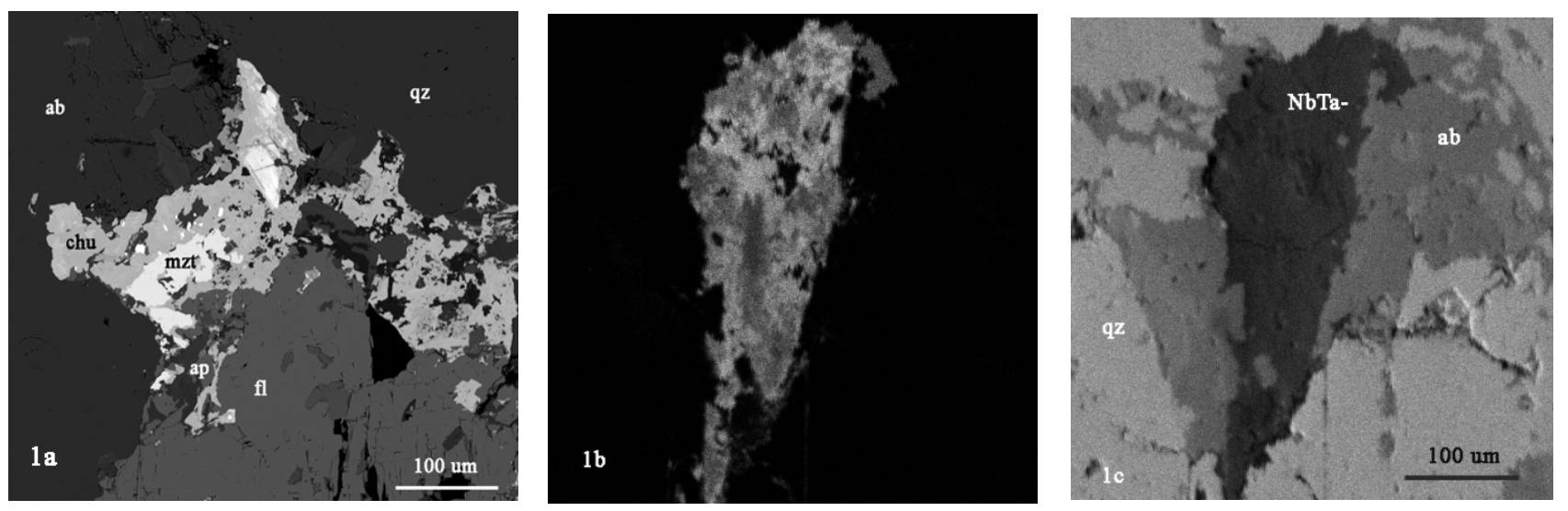

Figure 1. a) BSE image of phosphate shows monazite coated by churchite, ab-albite, qz-quartz, chuchurchite, mzt-monazite, ap-apatite, fl-fluorite. b) Ti map for NbTa oxide, Ti shows uneven distribution in the mineral. c) Oxygen map for $\mathrm{NbTa}$ oxide, low oxygen in $\mathrm{NbTa}$-oxide.
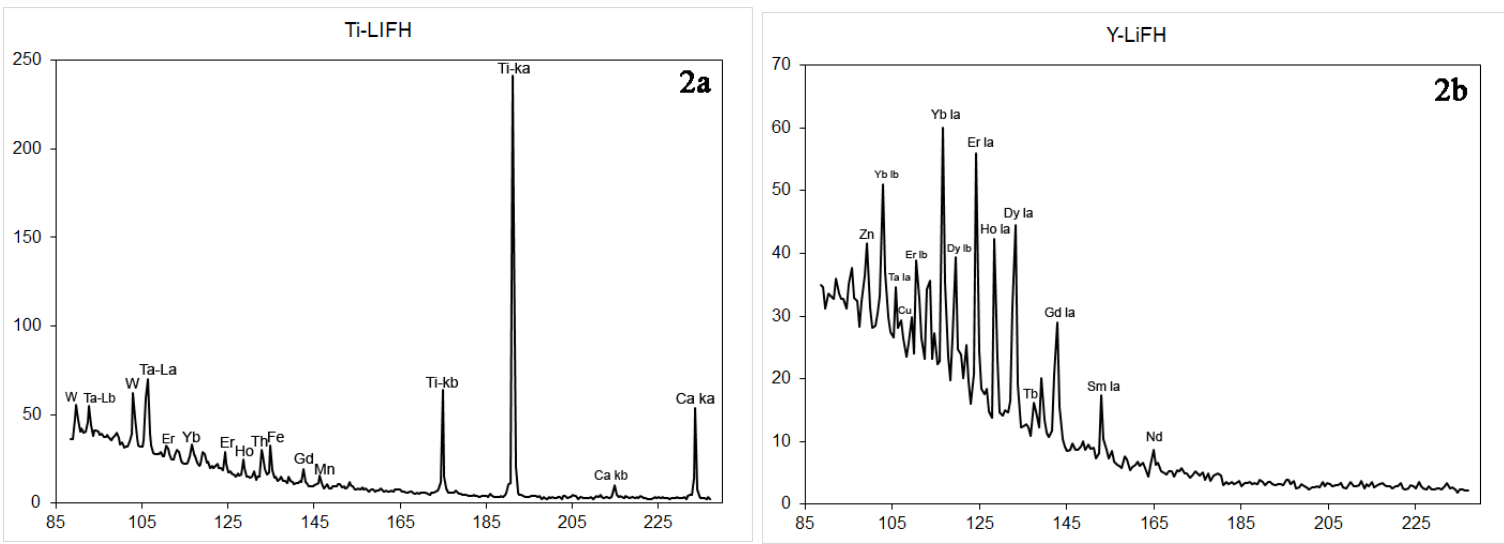

Figure 2. Wavescan for minerals with multielements to identify elements and help the selection of peak and background for quantitative analysis. a) $\mathrm{LiFH}$ wavescan for NbTa-oxides; b) LiFH wavescan for churchite. 